\section{Investigating conversion of endplate chondrocytes induced by intermittent cyclic mechanical unconfined compression in three-dimensional cultures}

\author{
H.G. Xu, ${ }^{1}$ W. Zhang, ${ }^{1}$ Q. Zheng, ${ }^{1}$ Y.F. Yu, ${ }^{2}$ \\ L.F. Deng, ${ }^{3}$ H. Wang, ${ }^{1}$ P. Liu, ${ }^{1}$ M. Zhang ${ }^{1}$ \\ 'Department of Orthopedic Surgery, \\ Yijishan Hospital, Wannan Medical \\ College, Wuhu, Anhu \\ ${ }^{2}$ The Key Laboratory of Stem Cell \\ Biology, Institute of Health Sciences, \\ Shanghai Institute for Biological Sciences, \\ Chinese Academy of Sciences and \\ Shanghai Jiao Tong University School of \\ Medicine \\ ${ }^{3}$ Shanghai Institute of Traumatology and \\ Orthopaedics, Department of \\ Orthopaedics, Ruijin Hospital Affiliated \\ to Shanghai Jiao Tong University, \\ Shanghai, China
}

\section{Abstract}

Mechanical stimulation is known to regulate the calcification of endplate chondrocytes. The Ank protein has a strong influence on anti-calcification by transports intracellular inorganic pyrophosphate (PPi) to the extracellular matrix. It is known that TGF- $\beta 1$ is able to induce Ank gene expression and protect chondrocyte calcification. Intermittent cyclic mechanical tension (ICMT) could induce calcification of endplate chondrocytes by decrease the expression of Ank gene. In this study, we investigated the relation of intermittent cyclic mechanical unconfined compression (ICMC) and Ank gene expression. We found that ICMC decreased the Ank gene expression in the endplate chondrocytes, and there was an decreased in the TGF- $\beta 1$ expression after ICMC stimulation. The Ank gene expression significantly increased when treated by transforming growth factor alpha 1 (TGF- $\beta 1$ ) in a dose-dependent manner and decreased when treated by SB431542 (ALK inhibitor) in a dose-dependent manner. Our results implicate that ICMC-induced downregulation of Ank gene expression may be regulated by TGF- $\beta 1$ in endplate chondrocytes.

\section{Introduction}

Intervertebral disc degeneration is one of the most common causes of low back pain. It manifests with osteophytes and loss of signal intensity on clinical magnetic resonance imaging (MRI). Several factors have been implicated or postulated in causing disc degeneration, including mechanical factors, ageing, genetic factors and nutrition. However, the pathophysiology of the disc degeneration process remains unclear. ${ }^{1}$

The intervertebral disc is the largest avascular tissue in the body. One of the main pathways for nutrients to reach the avascular nucleus pulpous is by diffusion from the blood supply of the vertebral body through the endplate cartilage. The endplate cartilage is a layer of hyaline cartilage lying between the vertebral body and the intervertebral disc. Endplate calcification could impede the passage of nutrients from the blood to the intervertebral disc, leading to alterations in mechanical material disc properties, endplate failure to maintain the nucleus pulposus and acceleration of the degenerative process of the intervertebral $\operatorname{disc}^{2,3}$

A series of changes in the disc have been observed with aging, such as endplate calcification and disc degeneration. ${ }^{4,5}$ Abnormal endplate calcification is observed in a disc degeneration model of mechanical instability in the cervical or lumbar spine. We therefore speculate that changes in endplate calcification are related to mechanical stress. In our previous study, we demonstrated that short-term appropriate continuous cyclic mechanical tension (CCMT) could protect endplate chondrocytes calcification, ${ }^{6}$ but excessive intermittent cyclic mechanical tension (ICMT) could induce calcification of endplate chondrocytes. Tensile mechanical stimulation could alter Ank gene expression. ${ }^{7}$ However, it is unknown whether mechanical compressive applications elicit the same effect and which signaling pathways are involved in this process.

Many genes associated with cartilage calcification are known, including COL9A2, COL9A3, AGCI, CLIP, TNAP, Ank and transforming growth factor beta 1 (TGF- $\beta 1$ ). In a previous study, the authors found that Ank expression at both mRNA and protein level were lower in the human degenerative cervical endplate compared with the normal cervical endplate. ${ }^{8}$ However, changes in expression of the Ank gene remain unclear in mechanical-stimulated endplate chondrocytes. TGF- $\beta 1$ plays an important role in crystal deposition in endplate cartilage; it is a potent regulator of cell proliferation and a modulator of cell interactions with the extracellular matrix (ECM). TGF- $\beta 1$ is also able to induce extracellular pyrophosphate (ePPi) up-regulation via TGF- $\beta 1$-induced Ank gene expression., ${ }^{4,7}$

In this study, we hypothesized that ICMC alter Ank gene expression maybe regulated by TGF- $\beta 1$ in endplate chondrocytes in vitro, prior
Correspondence: Dr. Hong-Guang Xu, Department of Orthopedic Surgery, Yijishan Hospital, Wannan Medical College, Wuhu, Anhui 241001, China. Tel. +86.13855356303 .

E-mail: xuhg@medmail.com.cn

Key words: Endplate chondrocytes, ICMC, Ank, TGF- $\beta$.

Fundings: this study was supported by the Chinese National Natural Sciences Fund Project $(30973025,81272048,81311130314)$ and the Chinese Anhui Province Natural Science Fund Project (1308085MH152).

Received for publication: 8 April 2014. Accepted for publication: 12 June 2014.

This work is licensed under a Creative Commons Attribution NonCommercial 3.0 License (CC BYNC 3.0).

(C) Copyright H.G. Xu et al., 2014

Licensee PAGEPress, Italy

European Journal of Histochemistry 2014; 58:2415 doi:10.4081/ejh.2014.2415

to detection of Ank mRNA expression by realtime polymerase chain reaction (RT-PCR) and Ank protein expression by Western blotting. The role of TGF- $\beta 1$ in regulating expression of Ank was examined by measuring the expression upon pretreatment with TGF- $\beta 1$ and SB431542, a selective activin receptor-like kinase (ALK) receptor inhibitor. Chondrocyte cytoskeleton changes after ICMC stimulation were investigated by phalloidin staining and confocal microscopy.

\section{Materials and Methods}

\section{Chondrocyte isolation and culture}

Primary chondrocytes were isolated from lumbar spine endplate cartilage of SpragueDawley rats (8-10 weeks, 160-180 g). Cartilage from the L1-L5 endplate was carefully removed from the vertebrae and minced into small pieces $\left(<0.03 \mathrm{~mm}^{3}\right)$. This method is detailed in our previous paper. ${ }^{9}$ Primary endplate chondrocyte morphology was assessed using an inverted microscope (Figure 1C). Second passage (P2) cells were used experimentally. ${ }^{10}$ The study was carried out in strict accordance with the recommendation of the Guide for the Care and Use of Medical Laboratory Animals (Ministry of Health, China). This study protocol was approved by the Medical Laboratory Animals Care and Use Committee of Anhui Province and the Ethics Committee of Yijishan Hospital of Wannan Medical College and in accordance with the guideline for the Chinese ethical conduct in care and use of animals. 


\section{Preparation of rat endplate chon- drocytes into agarose constructs}

After cell trypsinizing and counting, rat endplate chondrocytes (P2) were suspended in commercial serum-free medium, UltraCulture (Cambrex, East Ruthurford, NJ, USA) supplemented with $1 \%$ antibiotics and $0.29 \mathrm{mg} / \mathrm{mL} \mathrm{L}$ glutamine. with an equal volume of $4 \%$ (wt/vol) agarose solution in DMEM at $37^{\circ} \mathrm{C}$ to produce a final cell solution of $10^{7}$ cells $/ \mathrm{mL}$. Cell-agarose constructs ( $8 \mathrm{~mm}$ diameter by 1.5 $\mathrm{mm}$ thick) were formed by casting the cellagarose mixture in a custom-designed mold and gelling for $10 \mathrm{~min}$ at room temperature. ${ }^{11}$ Based on calculations from the biphasic model, the mechanical responses of the agarose disks can be considered to reach equilibrium after 200 cycles of loading in the configuration described in Figure 1A.

\section{Three-dimensional cultures and application of cyclic mechanical pressure}

Cell-agarose mixtures were plated at a density of $10^{7}$ cells $/ \mathrm{mL}$ in $2 \mathrm{~mL}$ of medium on a BioPress $^{\mathrm{TM}}$ compression culture plate coated with collagen type I (Flexcell Int. Corp., Hillsborough, NC, USA) (Figure 1B). Cells were cultured for $48 \mathrm{~h}$ and then mechanical strain was applied, at which time the growth medium was replaced. A cyclic mechanical strain of $1 \mathrm{~Hz}$ sinusoidal curve at $10 \%$ elongation was applied using an FX-5000T'TM Flexercell $^{\circledR}$ Tension Plus ${ }^{\mathrm{TM}}$ unit (Flexcell Int. Corp). In the proper experiments the chondrocytes were stimulated by TGF- $\beta 1(10 \mathrm{ng} / \mathrm{mL})$ or SB431542 $(50 \mu \mathrm{M})$ accompanied by ICMC treatment. Experiments were conducted for 5 and 10 consecutive days. Endplate chondrocytes were exposed to mechanical strain $4 \mathrm{~h} /$ day and cultured for 5 days more. Cells were incubated in a humidified atmosphere at $37^{\circ} \mathrm{C}$ and $5 \%$ $\mathrm{CO}_{2}$ (balanced with $90 \% \mathrm{~N}_{2}$ ) with the $\mathrm{pH} 7.2^{12}$ and culture medium was changed every 2-3 days. Cells were harvested immediately after ICMC stimulation was applied.

\section{Cell viability, proliferation and apoptosis assay}

Agarose constructs were fixed in acetone and dehydrated in $10 \%, 20 \%$ and $30 \%$ sucrose, prior to embedding in optimal cutting temperature (0.C.T 4583, Sakura, Tokyo, Japan) and sectioning. A LIVE/DEAD ${ }^{\circledR}$ viability/cytotoxicity kit (Invitrogen, Carlsbad, CA, USA) was used to detect viable cells. For proliferation assay, end plate chondrocytes were seeded on Bio FlexTM plates and allowed to reach about $80 \%$ confluence, and then treated with 10\% ICMC. According to manufacturer's instructions, cell proliferation were assessed by AlamarBlue assay (Invitrogen). The cells were incubated in medium supplemented with $10 \%$ (v/v) Alamar Blue fluorescent dye for $2 \mathrm{~h}$ at time point 6,12 , 24,48 and $72 \mathrm{~h}$, respectively, upon 10\% ICMC in a humidified atmosphere at $37^{\circ} \mathrm{C}$ and $5 \% \mathrm{CO}_{2}$. Then, a $200 \mathrm{~mL}$ sample of the medium was transferred and the absorbance at 570 and 590 $\mathrm{nm}$ measured in a 96-well plate, using a
Multiscan UV visible spectrophotometer (Safire2; TECAN, Mannedorf, Switzerland). Non-seeded BioFlexTM plates with the same medium were used as blanks. Cells with $6 \mathrm{~h}$ ICMC loading served as control. For apoptosis, chondrocytes were seeded and allowed to reach about $80 \%$ confluence, and then ICMC treated or without treatment for 3 days. TUNEL staining was performed using Cell Death Detection kit (Roche, Mannheim, Germany) according to manufacturer's instructions. Statistic analysis was performed by cell counting.

\section{Real-time RT-PCR}

Total RNA was extracted from the cellagarose constructs using Trizol reagent (Invitrogen), according to manufacturer's instructions. Samples were homogenized in Trizol using a glass homogenizer, then incubated for $5 \mathrm{~min}$ at room temperature. After vigorous mixing with chloroform for $30 \mathrm{~s}$, the mixture was separated into a lower phenolchloroform phase and an upper aqueous phase

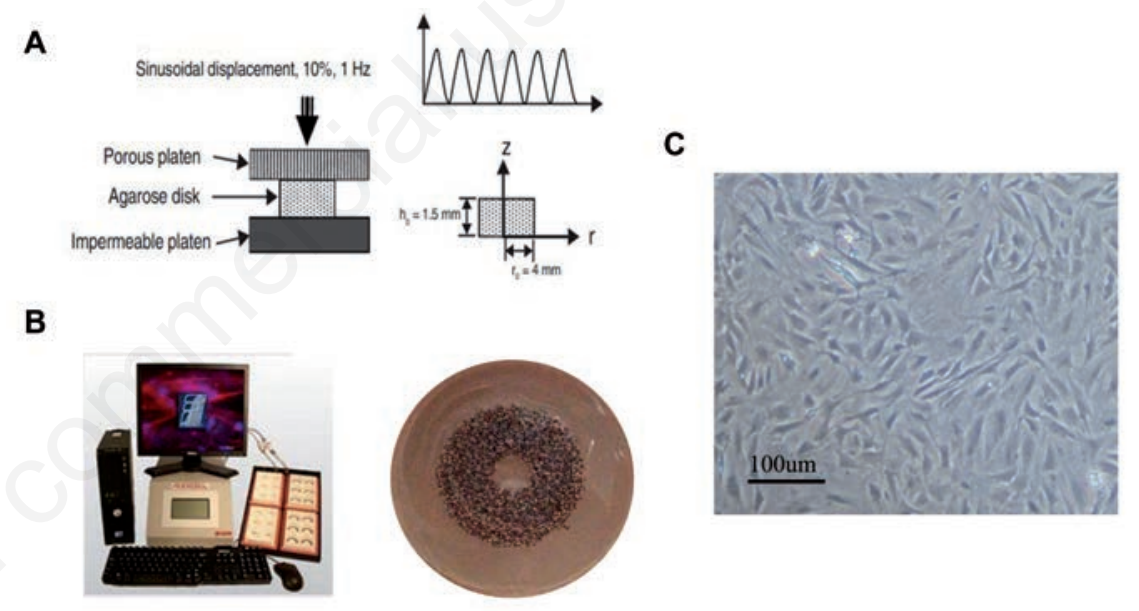

Figure 1. Three-dimensional cultures and application of cyclic mechanical pressure. A) Schematics of the bioreactor. B) Loading configuration of the unconfined compression test. C) Endplate cartilage cell morphology observed using inverted phase contrast microscopy.

Table 1. Sequences of primers used in the Real-Time reverse transcription-polymerase chain reaction.

\begin{tabular}{lcccc} 
Genes & Forward primer & Reverse primer & Accession number & Product length (bp) \\
Aggrecan & ACACCCCTACCCTTGCTTCT & AAAGTGTCCAAGGCATCCAC & NM_022190.1 & 124 \\
Type II collagen & CCTGAAACTCTGCCACCCAG & GTTCTTCCGAGGCACAGTCG & NM_012929.1 & 151 \\
\hline SOX-9 & TACTTCCAGTGGAATAGAAG & TGCGCCCACACCATGA & XM_001081628.2 & 69 \\
Type $X$ collagen & GAAACAGGTGTCTGACTTAC & TACTTCCAGTGGATAGAAG & XM_001053056.3 & 141 \\
\hline Type I collagen & CAGGCTGGTGTGATGGGATT & CCAAGGTCTCCAGGAACACC & NM_053304.1 & 278 \\
Osteocalcin & GCCCTGACTGCATTCTGCCTCT & TCACCACCTTACTGCCCTCCTG & NM_013414.1 & 103 \\
Ank & CAAGAGAGACAGGGCCAAAG & AAGGCAGCGAGATACAGGAA & NM_053714.1 & 177 \\
GAPDH & CTCAACTACATGGTCTACATGTTCCA & CTTCCCATTCTCAGCCTTGACT & NM_017008.3 & 81 \\
\hline
\end{tabular}


by centrifuging at $12,000 \times \mathrm{g}$ for $15 \mathrm{~min}$ at $4^{\circ} \mathrm{C}$. After the aqueous phase was transferred into a fresh tube, a pellet of RNA and agarose was formed by adding isopropyl alcohol for a 15min incubation at room temperature and centrifuging at $12,000 \times \mathrm{g}$ for $10 \mathrm{~min}$ at $4^{\circ} \mathrm{C}$. After washing and freezing in $75 \%$ ethanol at $-80^{\circ} \mathrm{C}$ overnight, the pellet was air-dried at room temperature and then homogenized in diethyl pyrocarbonate (DEPC)-treated water. Finally, the RNA solution was separated from the agarose by centrifuging the homogenized pellet solution at $12,000 \times \mathrm{g}$ for $15 \mathrm{~min}$ at $4^{\circ} \mathrm{C}$. The RNA product was then used for analysis of gene expression. RT-PCR was performed by a Roche Light Cycler 480 system using SYBR®Premix Ex Taq ${ }^{\mathrm{TM}}$ (Takara, Dalian, China) according to manufacturer's instructions. The primer sequences are shown in Table 1. All RT-PCR data were normalized to the $G A P D H$ gene for quantitative comparison.

\section{Western blotting analysis}

Agarose constructs were boiled in sample buffer consisting of $0.125 \mathrm{M}$ Tris- $\mathrm{HCl}, 5 \%$ sodium dodecyl sulfate (SDS), 10\% 2-mercaptoethanol, $20 \%$ sucrose and $0.04 \%$ bromphenol blue (100 $\mu \mathrm{L}$ buffer per construct) for $5 \mathrm{~min}$. The mixture was stored at $-80^{\circ} \mathrm{C}$ overnight and the protein solution was separated by centrifuging the mixture at $12,000 \times \mathrm{g}$ for $10 \mathrm{~min}$ at $4^{\circ} \mathrm{C}$. Aliquots of protein solution and positive control were run on a $10 \%$ SDS-polyacrylamide gel and subsequently transferred onto a polyvinylidene fluoride (PVDF) membrane (Millipore Corporation, Bedford, MA, USA) overnight at $4^{\circ} \mathrm{C}$. After transfer, the membrane was incubated $1 \mathrm{~h}$ in the blocking buffer consisting of TBST (20 mM Tris, $137 \mathrm{mM}$ sodium chloride and $0.1 \%$ polyoxyethylene sorbitan monolaurate) and $5 \%$ bovine serum albumin to eliminate nonspecific binding. The primary antibody used were rabbit monoclonal anti-Ank (Abcam, Cambridge, UK) at a dilution of 1:1000. For normalization of protein loading, GAPDH (Cell Signaling Technology, Danvers, MA, USA) rabbit monoclonal antibody was used at 1:5000 dilution. Incubated with goat anti-rabbit HRPconjugated secondary antibody (BD Biosciences, San Jose, CA, USA) at a dilution of 1:5000. The antigen-antibody complexes were visualized using the enhanced chemiluminescence detection system as re-commended by the manufacturer (Millipore). Immunoreactive bands were quantitatively analyzed in triplicate by normalizing the band intensities to GAPDH on scanned films with Alpha Image software.

\section{Immunofluorescence}

Constructs were embedded in 0.C.T. prior to sectioning. Subsequently, the sections of cells embedded in agarose were fixed with $4 \%$ paraformaldehyde and permeabilized with
$0.25 \%$ Triton X-100 for $20 \mathrm{~min}$. The whole sections were then blocked with $3 \%$ BSA at room temperature for $1 \mathrm{~h}$; then sections were incubated overnight with a rabbit monoclonal antibody (Abcam) recognizing rat Ank, at a dilution of 1:100. Incubation with goat anti-rat fluorescein secondary antibody for $40 \mathrm{~min}$. DAPI is a DNA-binding dye used for nucleus staining. The F-actin cytoskeleton in endplate chondrocytes was stained with tetramethylrhodamine B isothiocyanate-conjugated phalloidin 1:500 (Sigma-Aldrich, St. Louis, M0, USA). Cells were visualized with a confocal microscope (LEICA TCSSP5, Wetzlar, Germany).

\section{Enzyme-linked immunosorbent assay}

Supernatants were collected from both nonloaded (NC) and ICMC group chondrocytes. To measure the concentrations of TGF- $\beta 1$ in pellet supernatants, each growth factor was quantified using a commercial enzyme-linked immunosorbent assay kit (ELISA; R\&D Systems, Minneapolis, MN, USA) following the manufacturer protocol, $1 \times 10^{5}$ cell were used in the ELISA experiments.

\section{Statistical analysis}

The Student $t$-test was performed using SPSS 16.0 software (SPSS, Chicago, IL, USA); results are reported as mean \pm SD. P-values less than 0.05 were considered significant.

\section{Results}

\section{Expression of osteogenic-related and cartilage-related genes}

Endplate chondrocytes lost their phenotype after ICMC stimulation. RT-PCR results showed a time-dependent downregulation of type II collagen, aggrecan and SOX-9 expression, and increase in type I collagen, type X collagen and osteocalcin in the ICMC group compared with the NC group (Figure 2).

\section{Chondrocyte viability, proliferation,} apoptosis and changes of phenotype after ICMC

To confirm that ICMC did not cause cell death of endplate chondrocytes, we investigated cell viability, proliferation and apoptosis of endplate chondrocytes after exposure to ICMC. Our data show that no significant changes occurred in cell viability, proliferation and apoptosis of endplate chondrocytes between $\mathrm{NC}$ and ICMC groups (Figure 3 A,C,D). Fluorescence labelling of phalloidin showed $\mathrm{F}$ actin cytoskeleton changes in endplate chondrocytes after ICMC. Furthermore, the cells became more elongated in shape over culture time (Figure 3B).
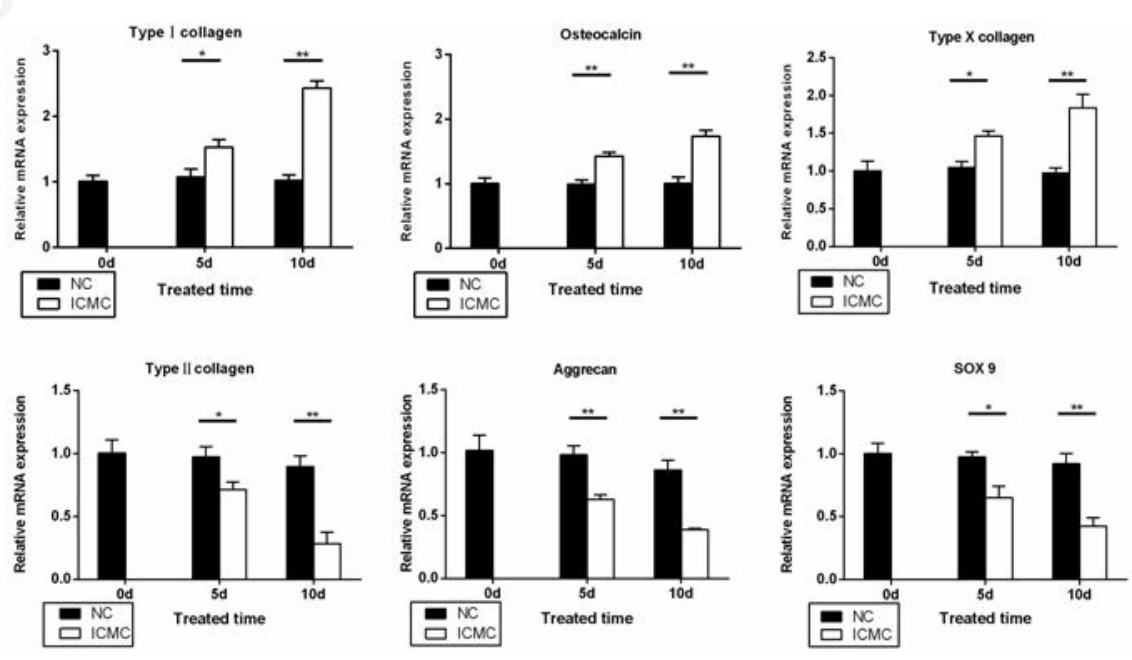

Figure 2. ICMC-induced calcification of endplate chondrocytes. RT-PCR shows expression of osteogenic-related and cartilage-related genes after ICMC. Data were presented as mean \pm SD. All experiments were repeated at least three times. ${ }^{*} P<0.05,{ }^{* *} P<0.01$. ICMC, intermittent cyclic mechanical compression loading; NC, ICMC non-loading. 0d, 5d, 10d, ICMC non-loading or loading for 5 and 10 days, $0 \mathrm{~d}$ as control. 


\section{Expression of Ank and TGF- $\beta 1$ after ICMC loading}

Ank expression at both mRNA and protein level decrease after ICMC loading in a timedependent manner (Figure 4 A,B). The transmembrane protein Ank was assessed using immunofluorescence. Compared with the NC group, Ank expression 5 and 10 days after ICMC loading was decreased (Figure 4C). At the same time, ELISA and RT-PCR showed that endogenous TGF- $\beta 1$ expression decreased in a time-dependent manner (Figure 5 A,B). Following ICMC treatment, chondrocytes were stimulated by TGF- $\beta 1$ (10 ng/mL), Ank mRNA and protein expression levels increased. However, Ank mRNA and protein expression levels decreased in the presence of SB431542 $(50 \mu \mathrm{M})$ and significantly upregulated in the presence of TGF- $\beta 1(10 \mathrm{ng} / \mathrm{mL}$ ) (Figure $5 \mathrm{C}, \mathrm{D})$.

\section{Discussion}

The current study demonstrates that ICMC decreases expression of the Ank gene and directly induces calcification of endplate chondrocytes. These findings indicate that downregulation of the Ank gene may be associated with downregulation of endogenous TGF- $\beta 1$.

\section{ICMC induced calcification and phenotype change of endplate chondrocytes}

During normal physiological movement of the spine, varying mechanical stimulation is important to regulate endplate chondrocyte matrix and intracellular homeostasis. The major proteoglycan in the disc is aggrecan, characteristic of its high anionic glycosaminoglycan content. The chondrocyte phenotype is mainly characterized by expression of genes coding for cartilage-related ECM molecules or their regulators, such as type II collagen, SOX9 and aggrecan, all of which are responsible for maintenance of cartilage anabolism. ${ }^{13,14}$ Compressive loading of rodent tail discs can result in cell death, impaired matrix synthesis, disruption of the anulus and vertebral body and accumulation of trabecular microdamage. ${ }^{15-17}$ Similarly, the high stress concentrations generated in the anulus after endplate damage would also be expected to inhibit matrix synthesis and increase production of matrix metalloproteinases (MMPs).$^{18}$ During disc degeneration, the balance of cell metabolism and matrix composition is broken, which is associated with a progressive loss of chondrocyte phenotype. ${ }^{19}$ After ICMC, endplate chondrocytes lose their differentiated phenotype, with expression of type II collagen, aggrecan and SOX-9 decreasing. ${ }^{20}$ Our results observed calci- fication of endplate chondrocytes in a disc degeneration model of mechanical stimulation after ICMC. Our previous study found that cervical endplate calcification was observed in disc degenerative patients and ICMT directly induced calcification of the endplate. ${ }^{7,21}$ However, there has been to date, no direct study on the relationship between calcification
A
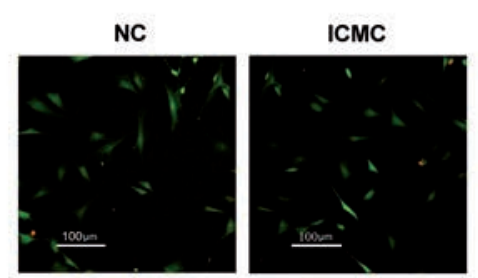

B
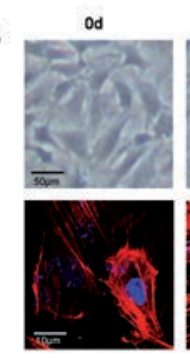

5d

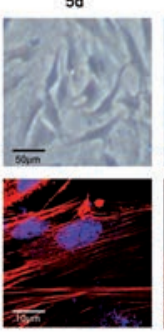

$10 \mathrm{~d}$

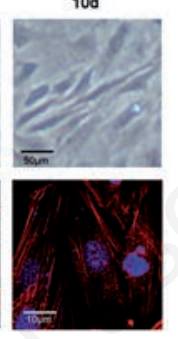

of the endplate and mechanical unconfined compression. Shi et al. found that expression of runx2 could be inhibited by continuous cyclic compression in mesenchymal stem cells (MSCs). ${ }^{22}$ MSCs could be induced to undergo osteogenic differentiation by intermittent mechanical tension (stress stimulation is applied to the intervertebral disc in disc degen-
Figure 3. ICMC did not affect the viability and apoptosis of endplate chondrocytes but altered chondrocyte morphology. A) After applying ICMC, viable (green) endplate chondrocytes are observed in both NC and ICMC groups. B) Sections of endplate cartilage cell morphology was observed by inverted phase contrast microscopy after applying ICMC; F-actin staining (red fluorescence), DNA staining (blue fluorescence); 0d, 5d, 10d, ICMC non-loading or loading for 5 and 10 days, $0 \mathrm{~d}$ as control. C) Cell proliferation was examined by Alamar Blue test. D) Apoptosis of endplate chondrocytes was examined by TUNEL staining (red fluorescence for apoptotic cells, blue fluorescence for nuclei). All experiments were repeated at least three times.
A

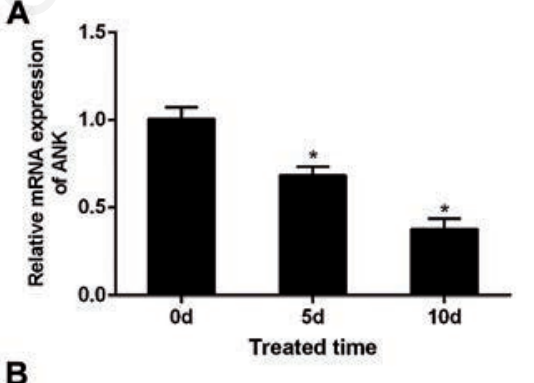

$B$

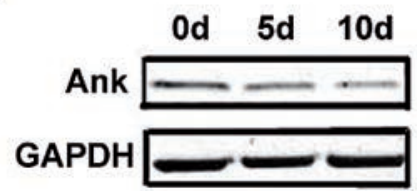

C
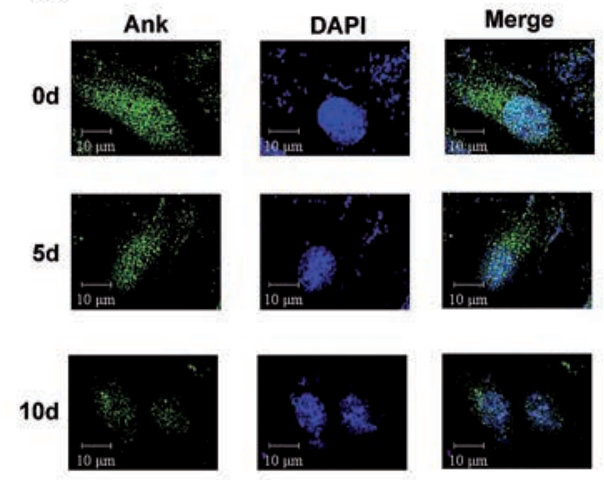

Figure 4. ICMC induced downregulation of $A n k$ expression. A) RT-PCR shows downregulation of $A n k$ expression among NC, 5d and $10 \mathrm{~d}$ groups. B) Western blotting shows downregulation of Ank expression among NC, 5d and 10d groups; columns represent mean $\pm \mathrm{SE} .{ }^{*} \mathrm{P}<0.05$. C) Transmembrane protein Ank (green) was assessed using immunofluorescence, blue for nucleus. Data were presented as mean $\pm S D, n \geq 3 .{ }^{*} P<0.05$. All experiments were repeated at least three times. 0d, 5d, 10d, ICMC non-loading or loading for 5 and 10 days, $0 \mathrm{~d}$ as control. 
eration for several minutes or hours/day). Our results demonstrate that ICMC directly induces degeneration of endplate chondrocytes with downregulation of cartilage marker genes, such as type II collagen, aggrecan and SOX-9 and upregulation of osteogenic marker genes such as type I collagen, type $\mathrm{X}$ collagen and osteocalcin. Type I collagen is the major component of the extracellular matrix in bone. Type X collagen is considered to be produced by hypertrophic chondrocytes during endochondral ossification and matrix calcification. Osteocalcin, as a bone $\gamma$ carboxyglutamic acidcontaining protein, is used as a biomarker for the bone formation process. ${ }^{23}$

\section{Intermittent cyclic mechanical unconfined compression down- regulated Ank expression through TGF- $\beta 1$}

Previous studies have demonstrated that pyrophosphate (PPi) is a potent inhibitor of basic calcium phosphate (BCP) crystal formation. Ank protein, a transporter able to export inorganic PPi from the cells (ePPi), is known to be upregulated in osteoarthritis. Ank is therefore a major contributor to cartilage calcification. ${ }^{24-26}$ However, few studies report expression of the human Ank gene in disc degeneration disease. ${ }^{27}$ Our previous study showed that the endplate expression of the Ank gene decreased in disc degeneration patients, and ICMC decreased expression of the Ank gene in rat lumbar endplate chondrocytes. ${ }^{7,921}$ Abnormal ePPi metabolism is associated with abnormal calcification and BCP deposition in articular tissues. ${ }^{28} \mathrm{PPi}$, as substrate for ALP, generates the Pi needed to induce the mineralization of cells. In Ank/Ank mice, BCP calcification in joints is associated with loss of Ank activity and diminished ePPi levels. ${ }^{29,30} \mathrm{We}$ speculate that Ank gene expression are involved synergistically in the process of calcification by ICMC.

In agreement with previous studies, ${ }^{31,32}$ our data shows that both mRNA and protein expression of TGF- $\beta 1$, the major extracellular PPi regulator, decreases with ICMC, consequently reduced expression of Ank at both mRNA and protein level. Our data also showed that Ank mRNA and protein expression increased with TGF- $\beta 1$-stimulation. We speculate that downregulation of the Ank gene may be caused by endogenous TGF- $\beta 1$ during ICMC-induced endplate chondrocyte calcification. This finding may provide a new approach to treat the intervertebral disc degeneration by mechanical compression.

There were several limitations in the current study. First, we speculated that ICMC increased the TGF- $\beta 1$ expression through the integrin pathway. However, we did not detect integrin expression. Second, ICMC may regulate Ank gene expression via multiple signaling pathways. However, we only investigated the TGF- $\beta 1$. Third, it remains unknown whether our results using endplate chondro-
A

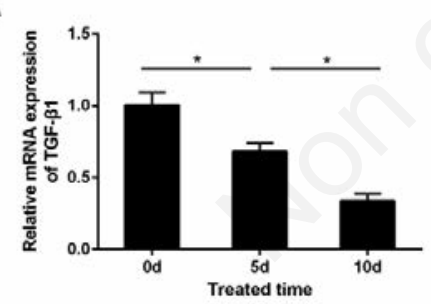

B

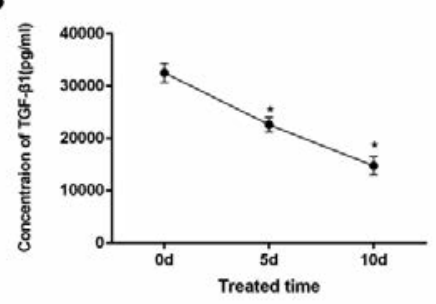

C

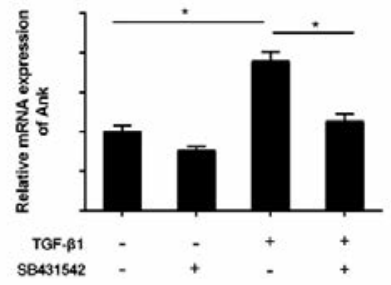

D

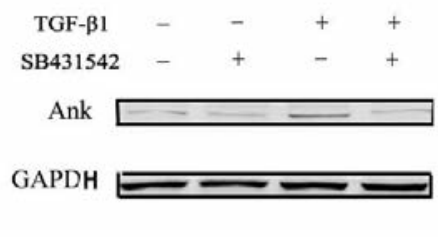

cytes in vitro represent the biologic behavior of human endplate chondrocytes exposed to mechanical stress in vivo. This is something we would like to investigate in future studies.

\section{References}

1. Loreto C, Musumeci G, Castorina A, Loreto C, Martinez G. Degenerative disc disease of herniated intervertebral discs is associated with extracellular matrix remodeling, vimentin-positive cells and cell death. Ann Anat 2011;193:156-62.

2. Masuda I, Hirose, J. Animal models of pathologic calcification. Curr Opin Rheumatol 2002;14:287-91.

3. Ho AM. Role of the mouse ank gene in control of tissue calcification and arthritis. Science 2000;289:265-70.

4. Bian Q, Liang QQ, Wan C, Hou W, Li CG, Zhao YJ, et al. Prolonged upright posture induces calcified hypertrophy in the cartilage end plate in rat lumbar spine. Spine (Phila Pa 1976) 2011;36:2011-20.

5. Peng B HS, Shi Q, Jia L. The relationship between cartilage enplate calcification a disc degeneration an experimental study. Chin Med J (Engl) 2001;114:308-12.

6. Xu H, Zhang X, Wang H, Zhang Y, Shi Y, Zhang $X$. Continuous cyclic mechanical tension increases ank expression in endplate chondrocytes through the TGF- $\beta 1$ and p38 pathway. Eur J Histochem 2013; $57: \mathrm{e} 28$.

7. Xu HG, Zhang XH, Wang H, Liu P, Wang LT, Zuo CJ, et al. Intermittent cyclic mechanical tension-induced calcification and downregulation of Ank gene expression of end plate chondrocytes. Spine (Phila Pa 1976) 2012;37:1192-7.

8. Xu HG, Yang M, Wang H, Jin S, Chen XW, Wang LT. [Altered expression of Ank protein in vertebral end plate].[Article in Chinese]. Zhonghua yi xue za zhi 2010; 90:1192-6.

9. Xu HG, Hu CJ, Wang H, Liu P, Yang XM, Zhang Y, et al. Effects of mechanical strain on Ank, ENPP1 and TGF-betal expression in rat endplate chondrocytes in vitro. Mol Med Rep 2011;4:831-5.

10. Veilleux NH YI, Spector M. Effect of passage number and collagen type on the proliferative, biosynthetic, and contractile activity of adult canine articular chondrocytes in type I and II collagen-glycosaminoglycan matrices in vitro. Tissue Eng 2004;10:119-27.

Figure 5. TGF- $\beta 1$ regulates expression of $A n k$ after ICMC. ELISA (A) and RT-PCR (B) shows downregulation of TGF- $\beta 1$ expression after applying ICMC. With ICMC application, the $A n k$ expression of both mRNA (C) and protein (D) was increased after TGF- $\beta 1$ stimulation. While treated with TGF- $\beta 1$ in the presence of SB431542, the Ank expression of both mRNA (C) and protein levels $(D)$ was decreased. Data were presented as mean \pm SD. ${ }^{*} \mathbf{P}<0.05$. All experiments were repeated at least three times. $0 \mathrm{~d}, 5 \mathrm{~d}, 10 \mathrm{~d}, \mathrm{ICMC}$ nonloading or loading for 5 and 10 days, $0 \mathrm{~d}$ as control.
11. Lehmann M, Martin F, Mannigel K, Kaltschmidt K, Sack U, Anderer U. Threedimensional scaffold-free fusion culture: the way to enhance chondrogenesis of in 
vitro propagated human articular chondrocytes. Eur J Histochem 2013;57:e31.

12. Collins JA, Moots RJ, Winstanley R, Clegg PD, Milner PI. Oxygen and pH-sensitivity of human osteoarthritic chondrocytes in 3-D alginate bead culture system. Osteoarthritis Cartilage 2013;21:1790-8.

13. Goldring MB. Update on the biology of the chondrocyte and new approaches to treating cartilage diseases. Best Pract Res Clin Rheumatol 2006;20:1003-25.

14. Zhao Q EH, Lefebvre V, De Crombrugghe B. Parallel expression of Sox9 and Col2a1 in cells undergoing chondrogenesis. Dev Dyn 1997;209:377-86.

15. Issever AS WA, Lu Y, Burghardt A, Lotz JC, Majumdar S. Micro-computed tomography evaluation of trabecular bone structure on loaded mice tail vertebrae. Spine (Phila Pa 1976) 2003;28:123-8.

16. Vernon-Roberts B, Pirie JC. Healing trabecular microfractures in the bodies of lumbar vertebrae. Ann Rheum Dis 1973; 32:406-12.

17. Walsh AJL, Lotz JC. Biological response of the intervertebral disc to dynamic loading. J Biomech 2004;37:329-37.

18. Handa T IH, Ohshima H, Osada R, Tsuji H, Obata K. Effects of hydrostatic pressure on matrix synthesis and matrix metalloproteinase production in the human lumbar intervertebral disc. Spine (Phila Pa 1976) 1997;22:1085-91.

19. Keorochana G, Johnson JS, Taghavi CE, Liao JC, Lee KB, Yoo JH, et al. The effect of needle size inducing degeneration in the rat caudal disc: evaluation using radiograph, magnetic resonance imaging, his- tology, and immunohistochemistry. Spine J 2010;10:1014-23.

20. Kanno T, Takahashi T, Tsujisawa T, Ariyoshi W, Nishihara T. Mechanical stress-mediated Runx2 activation is dependent on Ras/ ERK1/2 MAPK signaling in osteoblasts. J Cell Biochem 2007; 101:1266-77.

21. Xu HG, Li ZR, Wang H, Liu P, Xiang SN, Wang CD, et al. Intermittent cyclic mechanical tension-induced down-regulation of ectonucleotide pyrophosphatase phosphodiesterase 1 gene expression is mainly dependent on TGF-betal in end-plate chondrocytes. Orthop Surg 2013; 5:40-5.

22. Shi Y, Xia YY, Wang L, Liu R, Khoo KS, Feng ZW. Neural cell adhesion molecule modulates mesenchymal stromal cell migration via activation of MAPK/ERK signaling. Exp Cell Res 2012;318:2257-67.

23. Matuszewska A SJ. Evaluation of selected bone metabolism markers in rheumatoid arthritis patients. Adv Clin Exp Med 2013;22:193-202.

24. Hamade T, Bianchi A, Sebillaud S, Netter P, Jouzeau JY, Cailotto F. Inorganic phosphate $(\mathrm{Pi})$ modulates the expression of key regulatory proteins of the inorganic pyrophosphate (PPi) metabolism in TGFbetal-stimulated chondrocytes. Biomed Mater Eng 2010;20:209-15.

25. Hirose J, Ryan LM, Masuda I. Up-regulated expression of cartilage intermediate-layer protein and ANK in articular hyaline cartilage from patients with calcium pyrophosphate dihydrate crystal deposition disease. Arthritis Rheum 2002;46:3218-29.

26. Johnson K, Terkeltaub R. Upregulated Ank expression in osteoarthritis can promote both chondrocyte MMP-13 expression and calcification via chondrocyte extracellular PPi excess. Osteoarthritis Cartilage 2004; 12:321-35.

27. Xu HG, Cheng JF, Peng HX, Lv K, Wang H, Liu P, et al. JNK phosphorylation promotes natural degeneration of cervical endplate chondrocytes by down-regulating expression of ANK. Eur Rev Med Pharmacol Sci 2013;17:2335-44.

28. Costello JC, Rosenthal AK, Kurup IV, Masuda I, Medhora M, Ryan LM. Parallel regulation of extracellular ATP and inorganic pyrophosphate: roles of growth factors, transduction modulators, and ANK. Connect Tissue Res 2011;52:139-46.

29. Fong H, Foster BL, Sarikaya M, Somerman MJ. Structure and mechanical properties of Ank/Ank mutant mouse dental tissues - an animal model for studying periodontal regeneration. Arch Oral Biol 2009;54:570-6.

30. Las Heras F, Pritzker KP, So A, Tsui HW, Chiu B, Inman RD, et al. Aberrant chondrocyte hypertrophy and activation of betacatenin signaling precede joint ankylosis in Ank/Ank mice. J Rheumatol 2012;39: 583-93.

31. Speer MY, McKee MD, Guldberg RE, Liaw L, Yang HY, Tung E, et al. Inactivation of the osteopontin gene enhances vascular calcification of matrix gla protein-deficient mice: evidence for osteopontin as an inducible inhibitor of vascular calcification in vivo. J Exp Med 2002;196:1047-55.

32. Wood MA YY, Thomas PB, Haj AJ. Using dihydropyridine-release strategies to enhance load effects in engineered human bone constructs. Tissue Eng 2006;12:2489-97. 